Egyptian

Orthodontic Journal

\title{
SHEAR BOND STRENGTH OF METAL BRACKETS BONDED TO ENAMEL SURFACE AND TWO ESTHETIC RESTORATIVE MATERIALS
}

\author{
AHMED A. EL-BIALY* \\ AHMED ATTIA **
}

\section{ABSTRACT}

The orthodontist my be faced with the need to bond brackets to esthetic restorations. This is due to increasing demands of adults to orthodontic treatment. Bond strength of the brackets to the restored teeth should be within the range of clinical acceptance and without endangering the restoration during removing the brackets. So, it was necessary to evaluate the bond strength of the orthodontic brackets to these esthetic restorative materials in comparison to the natural teeth. This in-vitro study evaluated the shear bond strength(SBS) of metal orthodontic brackets to two esthetic restorative materials(malliable composite 6locks (MZ100) and machinable ceramics (Vita Mark II)) using a new luting cement used for bonding (compomer). Thirty six metal orthodontic brackets were bonded to a flat buccal surface of extracted premolars, MZ100 and Vita Mark II using the same luting agent. All specimens were stored in water for 45 days then thermocycled for 500 cycles. The SBS in Mpa was measured using Instron machine.

One way ANOVA showed statistically significant difference between test and control groups $\mathbb{P}=0.0006$. Mann-Whitney tests revealed statistically significant difference between (SBS) of control group and $M Z 100$ composite group $P=0.0003$, Also there was statistically significant difference between the two test groups

\footnotetext{
* Associate professor of orthodontics, Orthodontic department, Faculty of Dentistry, Mansoura University, Egypt.

${ }^{* *}$ Lecturer department of, Conservative Dentistry and Fixed Prosthodontics, Faculty of Dentistry, Mansoura University, Egypt.
} 
Egyptian

Orthodontic Journal

MZ100 composite and Vita Mark II ( $P=0.02)$. However, there was no statistically significant difference between control group and Vita Mark II group $(\mathcal{P}=0.07)$. This study revealed that the median of SBS for metal brackets to esthetic substrates(MZ100 $=5.7$ and Vita Mark II=8) was significantly lower than that of the natural teeth (9.9 $\mathcal{M P a})$ 6ut, at the same time they were within the acceptable clinical range (6-10 Mp) (6). However, the SBS of the metal brackets to the porcelain substrates was superior to that of composite. It was concluded that compomer luting cement may be used for direct bonding of orthodontic metal brackets to esthetic restorations in clinical practice.

\section{INTRODUCTION}

Toothache and dental diseases are not the only factors motivating people to seek dental care. Patients today seek the so-called esthetic treatment of the teeth for better appearance and quality of $\operatorname{life}^{(1,2)}$. The Computer Aided DesignComputer Aided Manufacturing (CAD-CAM) is among the most recent advances in dental technology for direct fabrication of esthetic restorations from various materials such as Vita Mark II machinable ceramic and MZ100 millable composite resin ${ }^{(3,4)}$.

Orthodontist may be faced with many clinical situations which necessitates bonding of brackets to different types of these esthetic restorations ${ }^{(5)}$. This bond strength should be ranged from 6-10 Mpa shear strength to prevent bonding failure during treatment ${ }^{(6)}$. Bonding of the metal brackets to restoratives materials was handled by many ways, such as roughening the porcelain mechanically and etching using hydrofluoric acid to get surface roughness ${ }^{(7,8)}$. Recently, the introduction of one step luting agent has improved the orthodontic practice especially with adults who demands treatment while having different esthetic restorations ${ }^{(10,11,12)}$.

Compomer luting cements are recently developed luting agents which contains mostly composite resin with some glass ionomer chemistry (polyacidmodified composite resin luting cement) ${ }^{(13,14)}$. These cements have the following advantages, good mechanical properties, improved bonding capacity, fluoride release, ${ }^{(15)}$ could be used for cementation without preconditioning of tooth structure and restoration, less water absorption and less strength variation after water storage compared to resin-modified glass-ionomer cements ${ }^{(16)}$. 
This study was conducted to compare the shear bond strengths of metal orthodontic brackets to enamel surface and esthetic restorations using compomer luting agent.

\section{Materials and methods}

This study was applied on three groups. The first group; $(\mathrm{n}=12)$ cariesfree upper first premolars extracted during routine orthodontic treatment. The teeth were cleaned from soft tissues then stored in $0.1 \%$ thymol solution. Small area on the buccal surface was ground flat then polished with wet 400 and 600 grit silicon carbide abrasive paper.

The second group; $(\mathrm{n}=12)$ composed of malliable composite blocks (MZ100).

The third group; $(\mathrm{n}=12)$ were blocks of machinable ceramics (Vita Mark II).

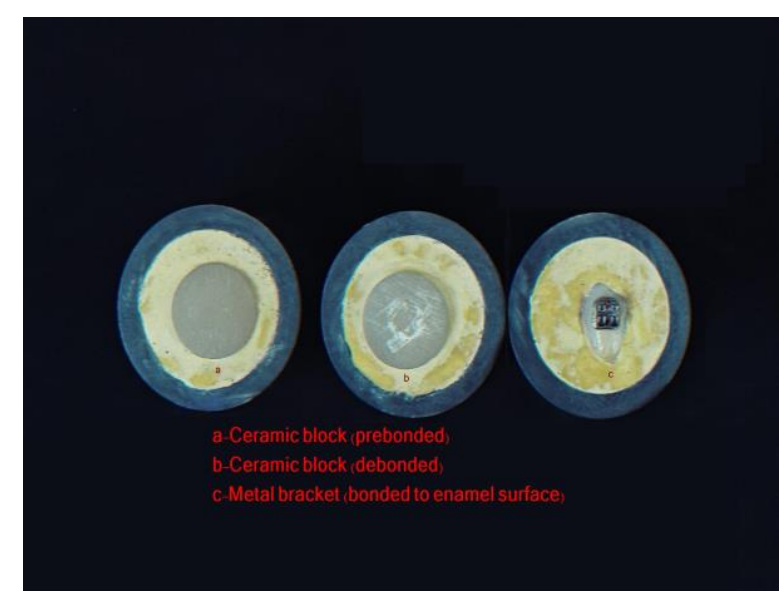

Fig.1. specimens used in the study

A total of thirty six metal brackets of lower incisor were divided into 3 groups $(n=12)$. The brackets were bonded to the extracted upper first

premolars (control group). Also, they were bonded to the other two groups; (MZ100 malliable composite blocks and Vita Mark II machinable blocks). A self-adhesive compomer luting cement (powder and liquid system in a translucent form) was used for bonding the brackets to the different substrates according to the manufacturer instructions. The recommended $\mathrm{P} / \mathrm{L}$ ratio (1 scoop P: 1drop L) were applied on mixing pad and mixed for 90 seconds. The creamy mix was applied to the bracket base and bonded to the substrate. 
Egyptian

Orthodontic Journal

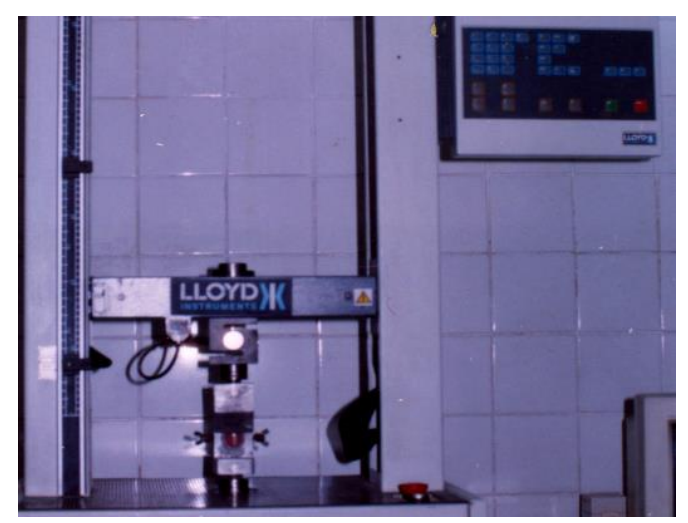

Fig.2: Lloyd Instron, L.S.500

One day after bonding the brackets, each specimen was embedded in a custom made metallic ring filled with fast setting stone so that, the bonded surface either of the teeth or blocks were cleared out of stone, and parallel to the base of the ring. All rings were washed with distilled water for 3 minutes, All specimens were

stored in water for 45 days at room temperature then thermo-cycled in water bath at $4{ }^{\circ} \mathrm{C}$ and $60^{\circ} \mathrm{C}$ with dwell time 30 seconds for 500 cycles. Each specimen was mounted on a universal testing machine and the shear force was applied to each specimen at the junction of the bracket/substrate interface using a knife-edge rod at a cross head speed of $0.5 \mathrm{~mm} / \mathrm{min}$. The Shear bond strength (SBS) was calculated by dividing the load at dislodgement in Newtons by the surface area of the bracket in $\mathrm{mm}$. Shear bond strength in Mpa were recorded for each specimen.

Table I: Materials used in the study

\begin{tabular}{|l|l|}
\hline \multicolumn{1}{|c|}{ Materials } & \multicolumn{1}{c|}{ Manufacturers } \\
\hline MZ100 malliable composite blocks & \multicolumn{1}{c|}{ 3M ESPE, Seefeld, Germany } \\
\hline $\begin{array}{l}\text { Vita Mark II } \\
\text { machinable ceramics }\end{array}$ & Vita, Bad Sackingen, Germany \\
\hline $\begin{array}{l}\text { Dyract } \\
\text { compomer luting cement }\end{array}$ & $\begin{array}{l}\text { Dyract Cemplus, Dentsply DeTrey, Konstanz, } \\
\text { Germany }\end{array}$ \\
\hline Orthodontics metal brackets & \multicolumn{1}{|c|}{ American orthodontics, Sheboygan, USA } \\
\hline
\end{tabular}

Volume 28 - December 2005 
Non parametric methods one way ANOVA, (Kruskal-Wallis test) and Mann-Whitney U tests were used for statistical analysis. The Kruskal-Wallis test was used first to detect overall significance and Mann-Whitney $U$ tests follow to identify which pairs of groups had the significant difference $(\mathrm{p} \leq 05)$.

\section{RESULTS}

The data of shear bond strength for different groups in MPa are shown in table I1. One way ANOVA (The Kruskal-Wallis test) showed statistically significant difference between test and control groups $\mathrm{P}=0.0006$. Mann-Whitney tests revealed that there was a statistically significant difference between (SBS) of control group and MZ100 composite group $\mathrm{P}=0.0003$. Also there was statistically significant difference between 2 test groups MZ100 composite and Vita Mark II P $=0.02$. However, there was no statistically significant difference between control group and Vita Mark II group $\mathrm{P}=0.07$.

Table II: Mean, standard deviations and median shear bond strength of different groups in MPa.

\begin{tabular}{|c|c|c|}
\hline Test groups & Mean+/- SD & Median \\
\hline Nat. teeth(NT) & $11 \pm 3.8$ & 9.9 \\
\hline Vita Mark (VMII) & $8.5 \pm 3.2$ & 8 \\
\hline MZ100(MZ) & $5.9 \pm 2.3$ & 5.7 \\
\hline
\end{tabular}

MZ : MZ100 malliable composite blocks

VMII: Vita Mark II machinable ceramic

NT : Natural Teeth

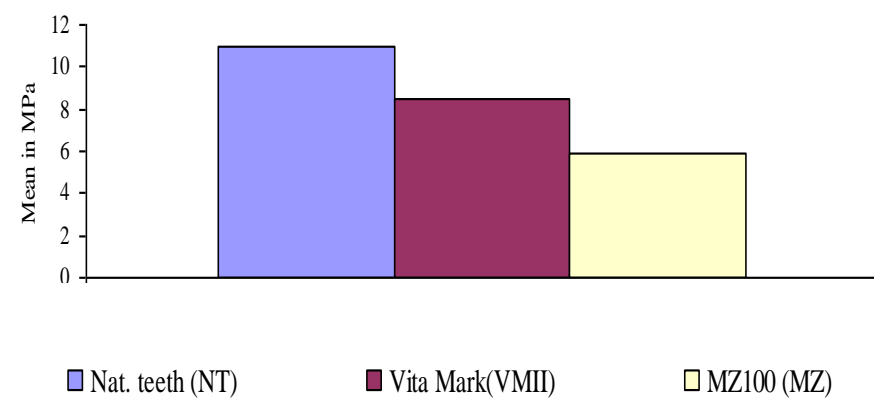

Fig.3 : Mean of the shear bond strength of different groups. 
Egyptian

Orthodontic Journal

\section{DISCUSSION}

Direct bonding of orthodontic attachments has improved the clinical practice of orthodontics ${ }^{(17)}$. The metallic bracket bonding to restoratives materials was handled in many ways as using diamond bur to rough the porcelain ${ }^{(8,18)}$, green stones ${ }^{(17)}$ or abrasive desks ${ }^{(18)}$, and finally direct bonding was used ${ }^{(9)}$. Some of these agents were toxic as hydrofluoric acid for the patient and staff ${ }^{(19)}$. Other adhesives introduced requires no etching I.e. one step bonding and proved reasonable bonding ability ${ }^{(10)}$.

The laboratory findings of this study revealed that the bond strength of metal brackets to the malliable composite restorative material was significantly lower than that of the natural teeth, However it was at the same time within the acceptable clinical range ${ }^{(6)}$. On the other hand, the SBS of the metal brackets to the porcelain substrates showed no significance difference compared with that of the natural teeth. This could be attributed to the fact that both esthetic substrates were mechanically polished and the composite blocks were more smooth in comparison to the ceramic blocks. More over this study was conducted without the use of any type of adhesives. Adding to these factors, the failure of bonding should be (cohesive) within the luting agent and without obvious chipping of the esthetic materials ${ }^{(19,20)}$.

Clinical implication of this study is that when adult patients seek for orthodontic treatment while having machinable ceramic or composite restorations. Compomer luting cement can be used for direct bonding of the metal brackets to these restored areas of teeth and tolerate the clinical required force.

\section{REFERENCES}

1. Christensen G. J: Ceramics vs. porcelain-fused-to-metal crowns: Give your patient a choice. J Am Dent Assoc. 1994; 125: 311-312.

2. Christensen G. J: Why all-ceramic crowns? J Am Dent Assoc. 1997; 128: 1453-1455.

3. Mörmann W. H., Bindl A: All-ceramic chair-side computer-aided design/computeraided machining restorations. Dent Clin North Am. 2002;46: 405-426

4. Raigrodski A. J: Contemporary all-ceramic fixed partial dentures: a review. Dent Clin North Am . 2004;48: 531-544.

5. Newman SM, Dressler KB, Grenadier MR: Direct bonding of orthodontic brackets to esthetic restorative materials using a silane. Am J Orthod Dentofacial Orthop. 1984;86:503-6. 
6. Reynolds, IR: A review of direct orthodontic bonding. Br. J Orthod 1975; 171-8.

7. Newman GV: Bonding to porcelain. J Clin Orthod 1983;17:53-5.

8. Pratt RC, Burgess JO, Schwartz RS, Smith JH: Evaluation of bond strength of six porcelain repair systems. J Prosth Dent. 1989; 62:11-3.

9. Wessam M : Acid-etch versus non acid-etch bonding-a comparative study. Egyptian Orthodontic Journal 2003;23:117-132.

10. Afify AR, Basyouni A: Ceramic brackets bonding using light-cured glass-ionomer adhesive. A clinical study. Egyptian Orthodontic Journal 2000;17:25-34.

11. Nicholson J W, McKenzie $\mathbf{M}$ A: The properties of polymerizable luting cements. J Oral Rehabil 1999; 26: 767-774.

12. Nicholson JW, Gjorgierska, Bajraktarova B, Mckenzie MA: Change in properties of polyacid-modiefied composites resins (compomers) following storage in acidic solutions. J Oral Rehabil 2003; 30:601-607.

13. Bishara S.E., VonWald L., Laffoon J.F, and Warren J: Effect of using new cyanoacrylate adhesive on the shear bond strength of orthodontic brackets. Angle Orthod. 2001;71:466-9.

14. Charuphan OB, Bishara SE and Read A: The effect of blood contamination on the shear bond strength of orthodontic brackets with a use of a new self-etch primer. 2003; 123:547-550.

15. Doron H, Shirley SD, Immanuel G, Itzchak Rand Meir R: Tensile bond strength of ceramic brackets bonded to porcelain facets. Am J Orthod Dentofacial Orthop.2003; 123:551-4.

16. Wilson P R, Stankiewicz N R: Effect of cement space and delayed placement on the seating of crowns luted with Vitremer, Fuji Duet and Dyract Cem. Am J Dent. 1998; 11: 240-244.

17. Eustaquio R, Garner LD, Moore BK: Comparative tensile strengths of brackets bonded to porcelain with orthodontic adhesive and porcelain repair system. Am J Orthod Dentofacial Orthop. 1988;94:421-5.

18. Kao EC, Johnston WM: Fracture incidence on debonding of orthodontic brackets from porcelain laminates.(Abstract)), J Prosthet Dent . 1991;66:631-7.

19. Rosenstiel S. F., Land M. F., Crispin B. J: Dental Luting agents: a review of the current literature. J Prosth Dent 1998; 80: 280-301.

20. Moin K. and Dogan IL: An evolutions of the shear bond strength, measurements of unfilled and filled combinations, 1978; 74:531-5. 